\title{
Aprendizaje vertical
}

\author{
Patricia M. Valdespino Castillo
}

\section{Resumen}

En los eventos de enseñanza y aprendizaje de nuestra vida, hay personajes que juegan papeles clave. Maestros, tutores, familiares, novelas, canciones, columnas periodísticas, a menudo nos ayudan a entender las cuestiones que rondan nuestra cabeza. Pero con frecuencia los rechazamos porque son mensajes o actitudes de gente mayor y el desfase generacional no nos deja entenderlos bien.

Los tiempos de la covid-19 nos tienen encerrados en casa y nos alertan que justamente "Ios viejos" son un grupo vulnerable. Además, se nos ha pedido que cuidemos a los abuelos.

Si tenemos la suerte de contar con una conexión de internet, aparentemente podemos aprender de todo lo que queramos con un clic. Esto podría llevarnos a explorar solamente lo que nos parece atractivo, fácil y cómodo. Con este testimonio, invito a reflexionar sobre el papel de los viejos en el aprendizaje de generaciones enteras. Intento llamar a la apertura hacia voces diversas y a entender que todos jugamos un papel para caminar hacia una sociedad más madura.

Palabras clave: aprender en casa, aprendizaje transgeneracional, riqueza cultural.

\section{VERTICAL LEARNING}

\begin{abstract}
In the teaching and learning events of our life, there are characters who play key roles. Teachers, mentors, relatives, novels, songs, newspaper columns, often help us understand the questions in our heads. However, we often reject them because they are messages or attitudes from older people and the generation gap does not allow us to understand them well.

The times of CoviD-19 have us locked up at home. They alert us that precisely "elderly people" are a vulnerable group. Also, we have been asked to take care of grandparents.

If we are lucky enough to have an internet connection, it seems that we can learn anything we want with just one click. This could lead us to explore only what we find attractive, easy and comfortable. With this testimony, I invite you to acknowledge on the role of the elderly in the learning of entire generations. I call for openness towards diverse voices and for the understanding that we all play a role in moving towards a more mature society.
\end{abstract}

Keywords: learning from home, transgenerational learning, cultural richness.

Recepción: 17/10/2020. Aprobación: 1/12/2020.

Dol: http://doi.org/10.22201/cuaieed.16076079e.2021.22.1.9

Universidad Nacional Autónoma de México, Coordinación de Universidad Abierta, Innovación Educativa y Educación a Distancia (CUAIEED) Este es un artículo de acceso abierto bajo la licencia de Creative Commons 4.0 cc)(1)(2) 
"Aprendizaje vertical"

Patricia M. Valdespino Castillo

Vol. 22, Núm. 1, enero-febrero 2021

Revista Digital Universitaria

Patricia M. Valdespino Castillo

pancronica@gmail.com

orcid.org/0000-0002-2998-4627

https://sites.google.com/view/pancronos/home

Investigadora postdoctoral en el Berkeley Lab en California. Estudió Biología en la UNAM, donde también realizó sus estudios de posgrado en Ciencias del Mar y Limnología. Su investigación se enfoca en los ciclos biogeoquímicos del planeta. Estudia ensambles microbianos acuáticos, con estrategias tanto clásicas como de nueva generación, integrando la genómica microbiana con la imagen química acoplada a luz de sincrotrón. Es una entusiasta de la ciencia y del arte como guías para trabajar por un mundo mejor.

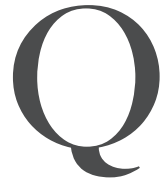

ue si me quedo en casa, que si atiendo mis clases, que si puedo cocinarme pollo. Mil kilómetros de distancia y mis padres quieren enseñarme todo.

No ven que ya no es como antes, hoy el aprendizaje es horizontal, en tiempo real. Puedes aprender de todo con un clic: algo superficial, profundo, en video, escrito, interactivo..., como tú quieras.

En otra época los familiares eran los maestros y entre más viejos, más maestros. Bueno, creo que ya ni es correcto llamarles viejos. Tercera edad, adultos mayores..., sí, jasí está mejor!

Ahora los viejos son personajes para las estadísticas. Son vulnerables, provocadores, obstinados, malhablados, lentos, malhumorados o extraoptimistas. Hay viejos que callan, viejos que nunca lo hacen. Además, ahora hay más tipos de viejos, los de la tercera, los de la cuarta edad.

Vocecitas irritantes, opinando de internet, de la desigualdad, del amor, de las mujeres. Esos que a veces mezclan una anécdota de la historia de los pueblos para decirte algo del pañal del bebé. O que de repente se quedan callados y se vacían de lágrimas así sin más. O que sueltan cualquier chiste verde sin miramientos. 
Hoy, después del enésimo noticiario del día sobre la covid, algo se me heló por dentro. No sé si será el sentimentalismo que trajo el encierro. O el vacío de lo "urgente" de cada día. Y extrañé las palabras de los viejos.

Tuve de repente nostalgia y hambre de viejos maestros, algunos que recientemente se han ido. De hecho, toda esta situación es tan confusa que me gustaría consultarlos. Probablemente saldrían con textos recontrarebuscados y excéntricos, pero igual me gustaría tenerlos cerca. Creo que me trae paz y me conforta saber que alguien está pensando.

Claro que me faltan Monsiváis, José Emilio, Marcelino, Leonard Cohen, tantos... Muchos que me dejaban con esa sensación de no estar entendiendo la película completa. Me faltan Gelman, Galeano, tan incansables como irrepetibles. Sampedro, que era como el abuelo que me guiaba por la eternidad. Gabo se ha ido también, con sus maravillas arrancadas de la tierra. Mundstock, Aute, Quino... Los tiempos de la covid se llevaron artistas con venas por las que circuló amor, miedo, hambre, pasión. Si se llevara a alguno más, sería insoportable.

Me pregunto si ha cambiado la forma de pensar.

Extraño más a mis queridos viejos, que parece que me preguntan: ¿qué pensaría yo en su lugar?

\section{Cómo CITAR ESTE ARTículo}

* Valdespino Castillo, Patricia M. (2021, enero-febrero). Aprendizaje vertical. Revista Digital Universitaria (RDU), 22(1). Dol: http://doi.org/10.22201/ cuaieed.16076079e.2021.22.1.9 